\title{
Texton Based Shape Features on Local Binary Pattern for Age Classification
}

\author{
B.Eswara Reddy \\ Associate Professor, CSE Dept, JNTUA COLLEGE OF ENGINEERING, ANANTAPUR, A.P, INDIA. \\ E-mail: eswarcsejntu@gmail.com \\ P.Chandra Sekhar Reddy \\ Associate Professor, CSE Dept, GIET COLLEGE OF ENGINEERING, RAJAHMUNDRY, A.P, INDIA. \\ E-mail: pchandureddy@yahoo.com \\ V.Vijaya Kumar \\ Dean Computer Science and Head SRRF, GIET, RAJAHMUNDRY, A.P, INDIA. \\ E-mail: vijayavakula@yahoo.com
}

\begin{abstract}
Classification and recognition of objects is interest of many researchers. Shape is a significant feature of objects and it plays a crucial role in image classification and recognition. The present paper assumes that the features that drastically affect the adulthood classification system are the Shape features (SF) of face. Based on this, the present paper proposes a new technique of adulthood classification by extracting feature parameters of face on Integrated Texton based LBP (IT-LBP) images. The present paper evaluates LBP features on facial images. On LBP Texton Images complex shape features are evaluated on facial images for a precise age classification.LBP is a local texture operator with low computational complexity and low sensitivity to changes in illumination. Textons are considered as texture shape primitives which are located with certain placement rules. The proposed shape features represent emergent patterns showing a common property all over the image. The experimental evidence on FGnet aging database clearly indicates the significance and accuracy of the proposed classification method over the other existing methods.
\end{abstract}

Index Terms - Shape features, LBP, Texton, Texture primitives, Emergent patterns

\section{INTRODUCTION}

Facial images are studied intensively in the literature for many applications like face recognition, predicting features of faces, reconstructing faces from some prescribed features, classifying gender, races and expressions from facial images, and so on. Facial aging has been an area of interest for decades [1,2,3,4,5,6], but it is only recently that efforts have been made to address problems like age estimation, age transformation, etc. from computational point of view $[7,8,9,10,11,12,13,14,15]$. Kwon and Lobo [8] classified input images as babies, young adults and senior adults based on cranio-facial development and skin wrinkle analysis. Some of the significant applications of studying age progression in human faces are face recognition across age (homeland security), automatic age estimation (parental control, age based Human-Computer interaction), prediction of one's appearance across age (finding missing individuals) etc. Developing models that characterize age progression in faces is a very challenging task. Facial aging effects are predominantly manifested in the form of shape variations during one's younger years and as wrinkles and other textural variations during one's older years [16].

Automatic age-progression is the process of modifying a face image in order to predict the future facial appearance of the corresponding person. In computer vision literature, age progression in human faces has been addressed from two perspectives: 1) Towards automatic age estimation and age based classification from face images [17]; 2) Towards computer-assisted age progression systems that could reliably predict one's appearance across age. The present paper focused on first. Automatic age progression involves the estimation of modification of the shape and texture features of a person's face in order to reflect cross-population age-related trends. The main issue in this subject is the accurate prediction of the facial appearance of a person along the time [18]. The present paper assumes that the ability to produce accurate age-classification depends on varying trends of shape features as age progresses. This ability has not been pursued in the computer vision community. To address this very important area of research, the present paper carried out the task of adulthood classification of a mug shot facial image into a child and adult. The present paper assumes the facial image of a person as a complicated texture. That's why new shape based texture classification methods is proposed on the ITLBP facial images. The FGnet [7] contains images from a wide variety of lighting conditions and age- 
groups. In addition, the number of images under a particular lighting condition is unbalanced.

The paper is organized as follows. The methodology is introduced in section II. In Section III, contains experimental results and some discussions. Concluding remarks are given in section IV.

\section{METHODOLOGY}

Texture, on its own does not have the capability of finding similar images, but it can be used to classify textured images from non-textured ones and then combined with another visual attribute like color to make the retrieval more effective. Analysis of texture requires the identification of those texture attributes which can be used for segmentation, discrimination, recognition, or shape computation. To evaluate micro texture features of face and to make texture features of face relatively invariant with respect to changes in illumination, image rotation, the present paper integrated the features of textons and LBP for age classification. The textons are having 1) a close relationship with image features 2) emergent patterns sharing a common property 3) local distribution properties. LBP represents precisely local textural information with respect to changes in illumination, image rotation. The proposed method of age classification consists of four steps as shown in the block diagram of figure 1 .

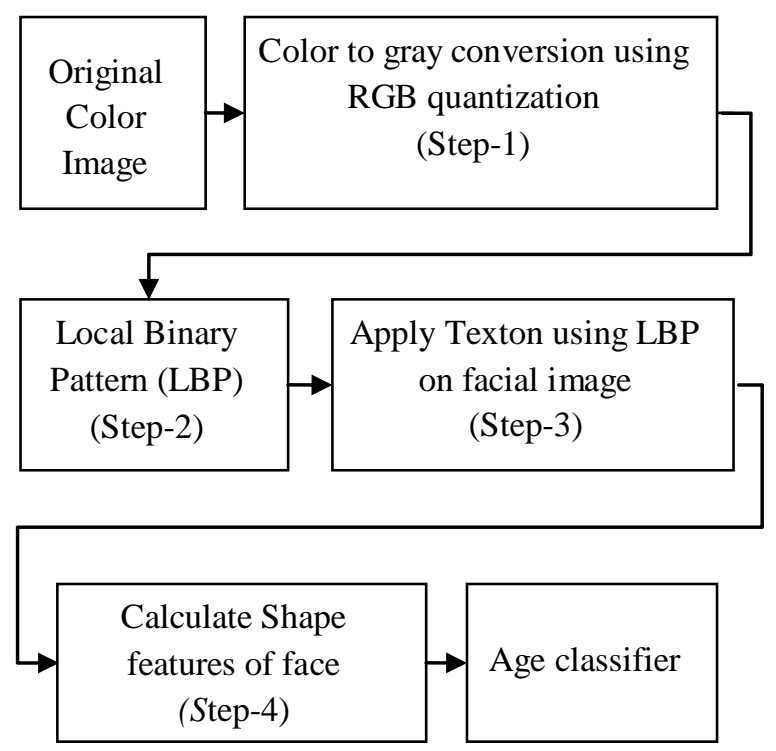

Figure1. Framework for age classification scheme using SF on ITLBP faces images

\section{A. Step -1: Color Quantization in RGB Color Space}

To convert color facial image into grey level facial image the present paper utilized RGB color quantization method. Color provides powerful information for texture classification and recognition even in the total absence of shape information. In order to extract grey level features from color information the proposed IT-LBP method utilized the RGB color space which quantizes the color space into 8-bins to obtain 256 grey levels. The index matrix of 256 color image is denoted as $\mathrm{C}(\mathrm{x}, \mathrm{y})$,given in the following Equation. Let $\mathrm{I}(\mathrm{R}), \mathrm{I}(\mathrm{G}), \mathrm{I}(\mathrm{B})$ be the index value of unit vectors along the $R, G$ and $B$ axes of $R G B$ color space.

$C(x, y)=32 * I(R)+4 * I(G)+I(B)$

where

$$
\begin{aligned}
& I(R)=0,0 \leq R \leq 32, \\
& I(R)=i,((32 * i)+1) \leq R \leq(32 *(i+1)) i=[1,2,3, \ldots, 7] \\
& I(G)=0,0 \leq G \leq 32, \\
& I(G)=i,((32 * i)+1) \leq G \leq(32 *(i+1)) i=[1,2,3, \ldots, 7] \\
& I(B)=0,0 \leq B \leq 64, \\
& I(B)=i,((64 * i)+1) \leq B \leq(64 *(i+1)) i=[1,2,3]
\end{aligned}
$$

Then each value of $\mathrm{C}(\mathrm{x}, \mathrm{y})$ is 8-bits binary code, ranging from 0 to 255 respectively.

\section{B. Step-2: Local Binary Pattern}

In step2 LBP is evaluated on the quantized facial image for obtaining local information in a precise way. Local Binary Pattern (LBP) is based on the concept of texture primitives. This approach is a theoretically, computationally simple and efficient methodology for texture analysis. To represent the formations of a textured image, the LBP approach, models $3 \times 3$ neighborhood as illustrated in figure 2 . A $3 \times 3$ circular neighborhood consists of a set of nine elements, $\mathrm{P}=$ $\left\{\mathrm{p}_{\mathrm{c}}, \mathrm{p}_{0}, \mathrm{p}_{1}, \ldots, \mathrm{p}_{7}\right\}$, where $\mathrm{p}_{\mathrm{c}}$ represents the gray level value of the central pixel and $p_{i}(0 \leq i \leq 7)$ represent the gray level values of the peripheral pixels. Each $3 \times 3$ circular neighborhood then, can be characterized by a set of binary values $b_{i}(0 \leq i \leq 7)$ as given in the following equation:

$\mathrm{b}_{\mathrm{i}}= \begin{cases}1 & \Delta \mathrm{p}_{\mathrm{i}}<0 \\ 0 & \Delta \mathrm{p}_{\mathrm{i}} \geq 0\end{cases}$

where $\Delta \mathrm{p}_{\mathrm{i}}=\mathrm{p}_{\mathrm{i}}-\mathrm{p}_{\mathrm{c}}$.

For each $3 \times 3$ neighborhood a unique LBP code is derived from the following equation:

$\mathrm{LBP}_{\mathrm{P}_{\alpha} \mathrm{R}}=\sum_{\mathrm{i}=0}^{\mathrm{i}=7} \mathrm{~b}_{\mathrm{i}} \times 2^{\mathrm{i}}$

Every pixel in an image generates an LBP code. A single LBP code represents local micro texture information around a pixel by a single integer code LBP $E[0,255]$.

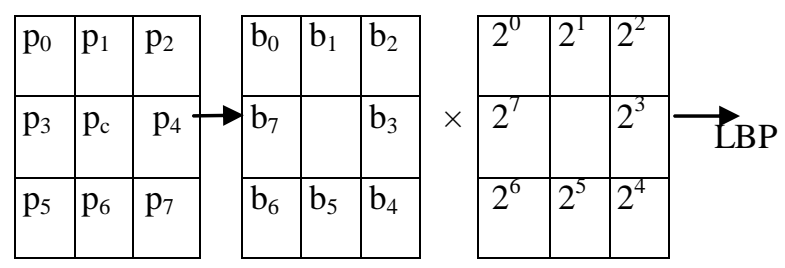

Figure2. Representation of LBP 
The $\mathrm{LBP}_{\mathrm{P}, \mathrm{R}}$ operator produces $2^{\mathrm{P}}$ different output values, corresponding to the $2^{\mathrm{P}}$ different binary patterns that can be formed by the $\mathrm{P}$ pixels in the neighbor set. Achieving rotation invariance, when the image is rotated, the gray values $g_{p}$ will correspondingly move along the perimeter of the circle, so different $L_{B B} P_{P, R}$ may be computed. To achieve rotational invariance a unique identifier to each LBP is assigned in the present paper as specified in the following equation:

$$
\operatorname{LBP}_{2}^{\mathrm{ri}} \mathrm{R}(\mathrm{x}, \mathrm{y})=\min \left\{\operatorname{ROR}\left(\mathrm{LBP}_{\mathrm{p}_{2} \mathrm{R}, \mathrm{i}}, \mathrm{i}\right)\right\}
$$

Where $\mathrm{i}=\{0,1,2,3, \ldots, \mathrm{P}-1\}$ and the superscript 'ri' stands for "rotation invariant". The function $\operatorname{ROR}\left(\mathrm{LBP}_{\mathrm{p}_{2}, \mathrm{R}}, \mathrm{i}\right)$ performs a circular bit-wise right shift on the P-bit number $\mathrm{LBP}_{p_{2} \mathrm{R}} \mathrm{i}$ times to the right $(|\mathrm{i}|<\mathrm{P})$.

\section{Step-3: Texton detection}

The term "texton" is conceptually proposed by Julesz [19]. It is a very useful concept in texture analysis and has been utilized to develop efficient models in the context of texture recognition or object recognition $[20,21]$. In step three textons are defined which are having a close relationship with image features and local distribution. Textons are considered as texture primitives which are located with certain placement rules. The textons are defined as a set of blobs or emergent patterns or shape features sharing a common property all over the image $[19,22]$. The different textons may form various image features. If the textons in the image are small and the tonal difference between neighbouring textons is large, a fine texture may result. If the textons are larger and concise of several pixels, a coarse texture may result. If the textons in image are large and consists of a few texton categories, an obvious shape may result. If the textons are greatly expanded in one orientation, pre-attentive discrimination is somewhat reduced. If the elongated elements are not jittered in orientation, the texton gradients at the texture boundaries are increased. To achieve this proposed IT-LBP utilized four texton types on a $2 \times 2$ grid as shown in figure 3 . In figure 3 the four pixels of a $2 \times 2$ grid are denoted as $V_{1}, V_{2}, V_{3}$ and $\mathrm{V}_{4}$. If two pixels are highlighted in gray color of same value, the grid will form a binary 1 texton otherwise a binary 0 texton. The four texton types used in the proposed IT-LBP approach are denoted as $\mathrm{T}_{1}, \mathrm{~T}_{2}, \mathrm{~T}_{3}$ and $\mathrm{T}_{4}$ respectively as shown in figure 3 . The working mechanism of texton detection is illustrated in figure 4 .

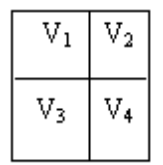

(a)

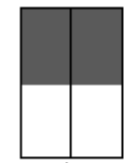

(b)

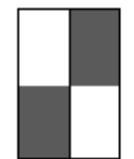

(c)

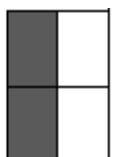

(d)

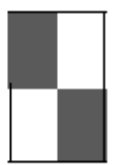

(e)
Figure3. Four special types of Textons: (a) $2 \times 2$ grid (b) $\mathrm{T}_{1}$ (c) $\mathrm{T}_{2}$ (d) $\mathrm{T}_{3}$ and $(\mathrm{e}) \mathrm{T}_{4}$

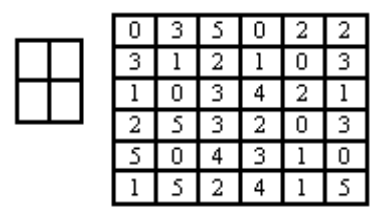

(a) (b)

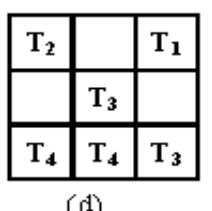

(d)

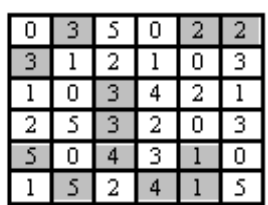

(c)

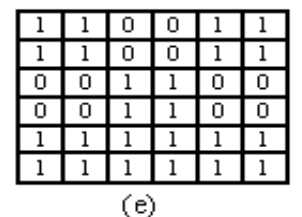

(e)

Figure4. Illustration of the Texton detection process: (a) $2 \times 2$ grid (b) Original facial image (c) \& (d) Texton location and Texton types (e) Texton image of the face.

\section{Step-4: Shape Features}

Shape, as a significant factor of objects, is an important research direction in image classification and recognition. As the age progresses certain shape features of face will be changing. IT-LBP captures the local information with low sensitive to changes in illumination and shape features located with certain placement rules. The present paper evaluated four complex curve shape features i.e $\mathrm{SF}_{1}, \mathrm{SF}_{2}, \mathrm{SF}_{3}$ and $\mathrm{SF}_{4}$ namely circle, ellipse, parabola and hyperbola respectively on IT-LBP facial images for a precise age classification. Frequency of occurrences of these four SF on IT-LBP facial images will be evaluated and tabulated for classification purpose.

The new set of shape features are shown in figure 5 and they are represented by the equations as given from (5) to (8). All the loci of points (with the exception of the circle) are considered, using different main directions, by introducing a rotation angle of $\beta$.

$$
\begin{aligned}
& \mathrm{SF}_{1}=\text { circle }=x^{2}+y^{2}=r^{2} \\
& \mathrm{SF}_{2}=\text { Ellipse }=\frac{x^{2}}{a^{2}}+\frac{y^{2}}{b^{2}}=1 \\
& \mathrm{SF}_{\mathrm{a}}=\text { Parabola }=\frac{-1}{\mathrm{c}} \mathrm{x}^{2}+2 \mathrm{c}=1 \\
& \mathrm{SF}_{4}=\text { Hyperbola }=\frac{\mathrm{x}^{2}}{\mathrm{a}^{2}}-\frac{y^{2}}{\mathrm{~b}^{2}}=1
\end{aligned}
$$

Where ' $r$ ' is the circle radius, ' $a, b$ ' are the semi major and semi minor axis lengths and ' $c$ ' is the distance between vertex and focus.

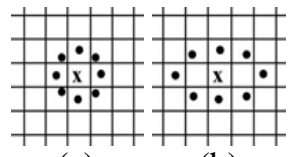

(a)

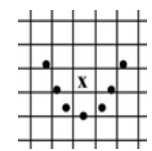

(c)

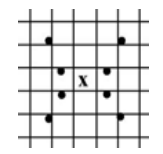

(d)
Figure5. Representation SF on a $5 \times 5$ neighborhood:(a) circle(b) ellipse(c) parabola (d) hyperbola

\section{EXPERIMENTAL RESULTS}

To show the significance of the proposed shape features (SF) on IT-LBP facial images the present paper considered various facial images. The facial images considered are 1000 images from FGnet aging 
database. Since it is not possible to show entire database, the present paper is chosen 36 facial images as sample data base from FGnet aging which are shown in figure 6. The present paper assumed that the childhood is from 0 to 18 years and from 19 years onwards as adulthood. To distinguish child faces from that of adult groups, a set of four shape features (SF) parameters i.e circle, parabola, ellipse and hyperbola are evaluated on IT-LBP facial images.

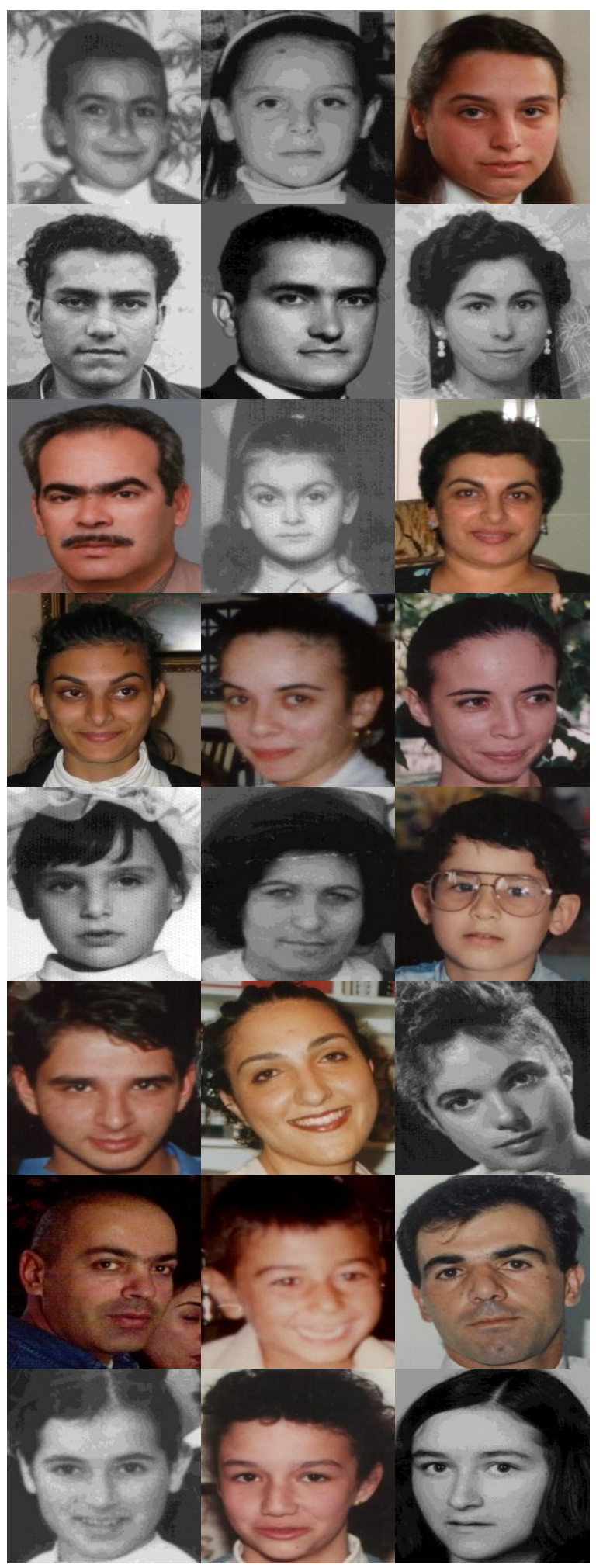

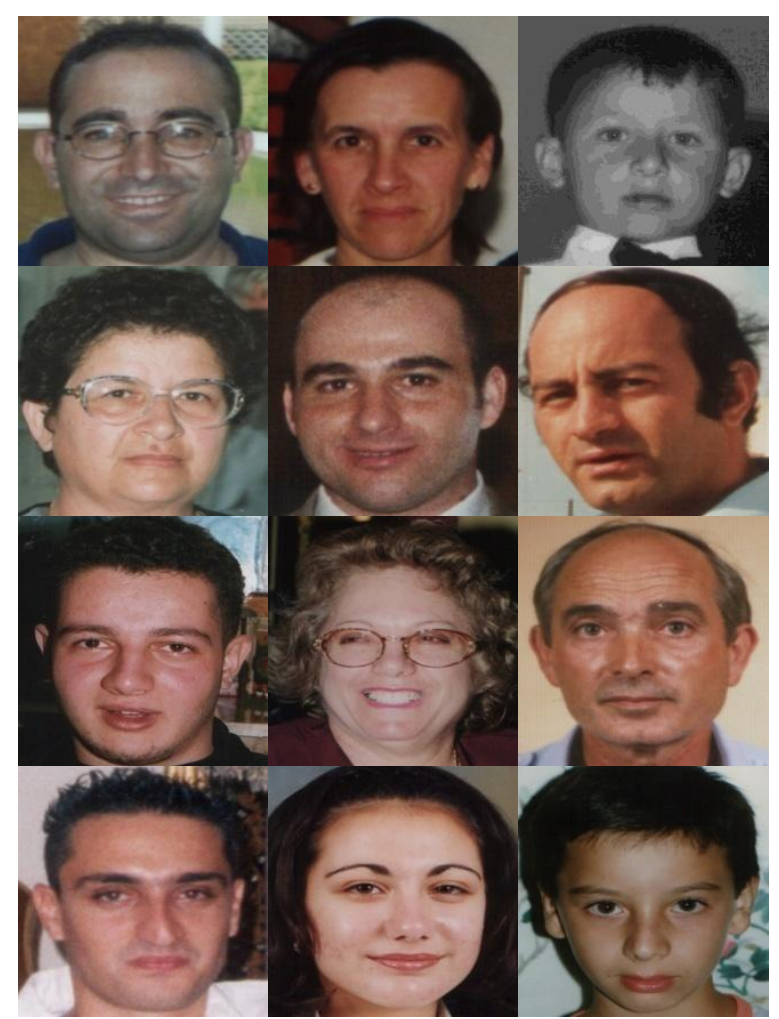

Figure6. 001A05, 002A05, 002A18, 004A21, 004A28, 005A18, 006A61, 008A08, 008A41, 010A18, 012A24, 012A30, 002A04, 032A13, 040A05, 041A19, 030A26, 047A13, 011A42, 023A05, 024A25, 025A12, 026A13, 027A16, 029A29, 034A44, 038A05, 039A50, 042A28, 045A32, 046A20, 047A55, 048A50, 051A24, 052A $14,035 \mathrm{~A} 12$

The frequency of occurrences of the proposed SF on the proposed IT-LBP facial images is listed in Table 1 and Table 2 for child and adults respectively. From the tables 1 and 2 it is clearly evident that as age progresses the frequency occurrences of SF on IT-LBP facial images shows an increasing trend. The increasing trend of SF is clearly visible from the graph of figure 7.From the figure 7 it is clearly evident that the above trend is more significant for the shape features $\mathrm{SF}_{3}$ and SF1. The present paper derived an algorithm for child and adulthood classification based on $\mathrm{SF}_{3}$ and $\mathrm{SF} 1$ features on IT-LBP facial images of Table $1 \& 2$.The proposed algorithm gives $95 \%$ of successful child and adulthood classification. The proposed method is compared with various other existing methods and listed in Table3.

Algorithm: Childhood and Adulthood classification based on Shape Features (SF) on IT-LBP facial mages

Begin

if $\left(\mathrm{SF}_{3}<=14\right)$ then

facial image is child

else

if $\left(\left(\mathrm{SF}_{3}>14 \& \& \mathrm{SF}_{3}<=18\right) \& \&\left(\mathrm{SF}_{1}<=17\right)\right)$ then facial image is Child

else

facial image is adult

End 
TABLE1. COMPUTED VALUES OF SF FOR SAMPLE CHILDHOOD IMAGES OF FGNET AGING DATABASE.

\begin{tabular}{|c|c|c|c|c|}
\hline Ages & $\mathrm{SF}_{1}$ & $\mathrm{SF}_{2}$ & $\mathrm{SF}_{3}$ & $\mathrm{SF}_{4}$ \\
\hline $001 \mathrm{~A} 04$ & 4 & 3 & 4 & 0 \\
\hline $002 \mathrm{~A} 04$ & 4 & 3 & 4 & 0 \\
\hline 014A03 & 4 & 2 & 3 & 5 \\
\hline 013A08 & 4 & 3 & 5 & 0 \\
\hline 014A03 & 5 & 3 & 5 & 0 \\
\hline $028 \mathrm{~A} 05$ & 5 & 0 & 3 & 5 \\
\hline 038A04 & 4 & 2 & 4 & 3 \\
\hline 011A07 & 5 & 2 & 6 & 0 \\
\hline 016A07 & 6 & 3 & 5 & 1 \\
\hline $015 \mathrm{~A} 07$ & 4 & 1 & 5 & 1 \\
\hline 008A08 & 7 & 0 & 4 & 3 \\
\hline 021A110 & 9 & 4 & 5 & 4 \\
\hline 032A10 & 8 & 4 & 6 & 0 \\
\hline 038A11 & 9 & 5 & 7 & 3 \\
\hline 047A12 & 9 & 6 & 7 & 1 \\
\hline 021A11 & 9 & 6 & 7 & 4 \\
\hline $025 \mathrm{~A} 12$ & 10 & 7 & 9 & 3 \\
\hline 014A12 & 9 & 5 & 10 & 3 \\
\hline 023A14 & 10 & 6 & 9 & 2 \\
\hline 026A13 & 11 & 8 & 10 & 4 \\
\hline 052A14 & 10 & 6 & 11 & 5 \\
\hline $062 \mathrm{~A} 12$ & 11 & 7 & 7 & 3 \\
\hline 016A16 & 15 & 11 & 16 & 6 \\
\hline 023A16 & 14 & 8 & 17 & 0 \\
\hline 013A16 & 14 & 9 & 13 & 4 \\
\hline 028A17 & 13 & 9 & 15 & 7 \\
\hline 012A18 & 17 & 10 & 14 & 5 \\
\hline 015A17 & 15 & 6 & 12 & 5 \\
\hline
\end{tabular}

TABLE2. COMPUTED VALUES OF SF FOR SAMPLE ADULTHOOD IMAGES OF FGNET AGING DATAB ASE.

\begin{tabular}{|c|c|c|c|c|}
\hline Ages & $\mathrm{SF}_{1}$ & $\mathrm{SF}_{2}$ & $\mathrm{SF}_{3}$ & $\mathrm{SF}_{4}$ \\
\hline 046A20 & 18 & 12 & 17 & 6 \\
\hline 051A22 & 19 & 13 & 18 & 7 \\
\hline 004A21 & 18 & 11 & 19 & 6 \\
\hline 006A22 & 17 & 10 & 16 & 7 \\
\hline 009A23 & 18 & 12 & 16 & 4 \\
\hline 012A24 & 19 & 9 & 17 & 0 \\
\hline 013A24 & 18 & 12 & 16 & 4 \\
\hline 051A24 & 19 & 13 & 19 & 0 \\
\hline 024A25 & 19 & 10 & 19 & 5 \\
\hline 027A25 & 20 & 15 & 18 & 7 \\
\hline 032A28 & 19 & 14 & 19 & 8 \\
\hline 004A28 & 18 & 11 & 20 & 5 \\
\hline 024A28 & 19 & 10 & 19 & 6 \\
\hline 061A29 & 20 & 12 & 19 & 7 \\
\hline 042A28 & 21 & 9 & 19 & 6 \\
\hline 018A29 & 23 & 8 & 19 & 10 \\
\hline 062A30 & 21 & 13 & 17 & 9 \\
\hline 012A30 & 19 & 6 & 24 & 12 \\
\hline 045A32 & 22 & 10 & 19 & 0 \\
\hline 029A33 & 22 & 13 & 18 & 6 \\
\hline 008A41 & 19 & 10 & 23 & 3 \\
\hline 006A42 & 21 & 12 & 25 & 5 \\
\hline 007A42 & 23 & 11 & 24 & 9 \\
\hline 028A46 & 22 & 14 & 20 & 6 \\
\hline 034A44 & 22 & 6 & 31 & 6 \\
\hline 047A43 & 19 & 10 & 29 & 0 \\
\hline 069A46 & 24 & 15 & 27 & 6 \\
\hline 039A50 & 28 & 12 & 30 & 10 \\
\hline 006A51 & 19 & 14 & 24 & 6 \\
\hline 005A52 & 25 & 8 & 24 & 8 \\
\hline
\end{tabular}

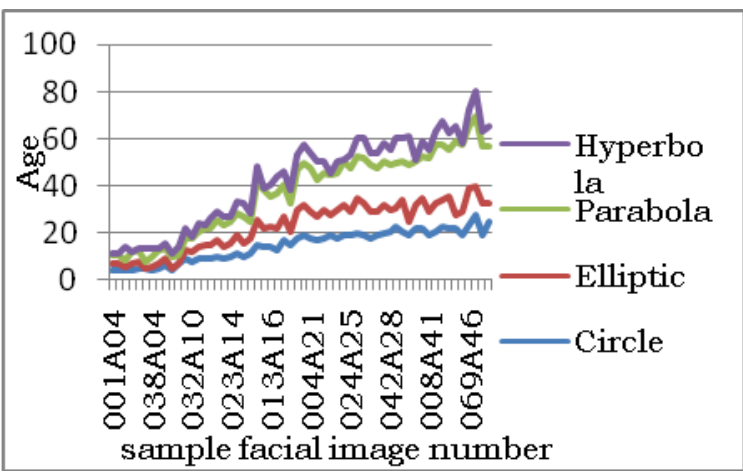

Figure7. Age classification of shape features.

TABLE3. COMPARISON WITH OTHER METHODS

\begin{tabular}{|c|c|c|c|c|}
\hline $\begin{array}{c}\text { S. } \\
\text { No }\end{array}$ & Authors & Name of the Method & $\begin{array}{l}\% \text { of } \\
\text { Classi } \\
\text { ficatio } \\
\mathrm{n} \\
\text { Rate } \\
\end{array}$ & $\begin{array}{l}\text { Type of Age } \\
\text { Classification }\end{array}$ \\
\hline 1 & $\begin{array}{l}\text { Proposed } \\
\text { Method }\end{array}$ & $\begin{array}{l}\text { Shape features on IT- } \\
\text { LBP }\end{array}$ & 95 & $\begin{array}{l}\text { Child and } \\
\text { Adulthood }\end{array}$ \\
\hline 2 & $\begin{array}{l}\text { Chandra } \\
\text { Mohan et } \\
\text { al, }\end{array}$ & \begin{tabular}{|c} 
Novel Method for \\
Child and Adulthood \\
Classification(CAC) \\
Based on Geometrical \\
Features of Facial \\
Image
\end{tabular} & 94.5 & $\begin{array}{l}\text { Child and } \\
\text { Adulthood }\end{array}$ \\
\hline 3 & $\begin{array}{l}\text { Chandra } \\
\text { Mohan et } \\
\text { al, }\end{array}$ & $\begin{array}{l}\text { Novel Method for } \\
\text { Child and Adulthood } \\
\text { Classification Using } \\
\text { Linear Wavelet } \\
\text { Transforms }\end{array}$ & 95.32 & $\begin{array}{l}\text { Child and } \\
\text { Adulthood }\end{array}$ \\
\hline 4 & $\begin{array}{l}\text { Chandra } \\
\text { Mohan et } \\
\text { al, }\end{array}$ & $\begin{array}{c}\text { Age Classification of } \\
\text { Adults Based on } \\
\text { Topological Texture } \\
\text { Features }\end{array}$ & 92.33 & $\begin{array}{c}16-25, \\
26-35, \\
36-45 \\
46-55, \\
56-65 \\
66-75 \text { and } \\
76-85\end{array}$ \\
\hline 5 & $\begin{array}{l}\text { Chandra } \\
\text { Mohan et } \\
\text { al, }\end{array}$ & $\begin{array}{c}\text { Novel Method of } \\
\text { Adult Age } \\
\text { Classification Using(2- } \\
\text { level) Linear Wavelet } \\
\text { Transforms }\end{array}$ & 93.8 & $\begin{array}{c}16-25 \\
26-35 \\
36-45 \\
46-55 \\
56-65 \\
66-75 \text { and } \\
76-85\end{array}$ \\
\hline 6 & $\begin{array}{l}\text { Young } \mathrm{H} . \\
\text { K won et } \\
\text { al, }\end{array}$ & $\begin{array}{l}\text { "Age Classification } \\
\text { from Facial Images," } \\
\text { Computer Vision and } \\
\text { Image understanding } \\
\text { Vol. } 74, \text { No. } 1 \text {,April, } \\
\text { pp. } 1-21,1999\end{array}$ & 78 & $\begin{array}{l}\text { Babies, adults, } \\
\text { and Senior } \\
\text { adults. }\end{array}$ \\
\hline 7 & $\begin{array}{l}\text { Tsuneo } \\
\text { KANNO } \\
\text { et al, }\end{array}$ & $\begin{array}{l}\text { "Classification of Age } \\
\text { Group Based on Facial } \\
\text { Images of Young } \\
\text { Males by Using Neural } \\
\text { Networks," IEICE } \\
\text { Trans. Inf \& Syst, } \\
\text { VolE84-D, No } \\
\text { 8,August 2001 }\end{array}$ & 80 & $\begin{array}{l}\text { Only young } \\
\text { males are age } \\
\text { groups } \\
\text { considered for } \\
\text { classifications } \\
\text { are } 12,15,18 \\
\text { and } 22 \text { years }\end{array}$ \\
\hline 8 & $\begin{array}{l}\text { Wen-Bing } \\
\text { Horng } \\
\text { Cheng-et } \\
\text { al, }\end{array}$ & $\begin{array}{c}\text { "Classification of Age } \\
\text { Groups Based on } \\
\text { Facial Features," } \\
\text { Tamkang Journal of } \\
\text { Science and } \\
\text { Engineering Vol. } 4 \\
\text { No. } 3 \text { 183-192(2001) }\end{array}$ & 90.52 & $\begin{array}{l}\text { Classified age } \\
\text { groups are } \\
\text { babies, young } \\
\text { adults, } \\
\text { middle-aged } \\
\text { adults, and old } \\
\text { adults }\end{array}$ \\
\hline
\end{tabular}




\section{CONCLUSION}

The Present paper evaluated complex shape features on a $5 \times 5$ mask using Integrated texton based LBP. The proposed method has low computational complexity and low sensitivity to change in illumination. The proposed complex shape features showing a steady increasing trend as age progress. This phenomenon reflects that as age progress there is a steady and gradual increase of wrinkle shapes on face. Many scholars evaluated pattern and shape based methods for age classification. The proposed IT-LBP approach is different from previous ones because, the complex shape features are evaluated on local texture operator LBP and on emergent patterns with close relationship with image features like Textons. The Table 3 reveals the high age classification rate of the proposed method when compared to other methods.

\section{ACKNOWLEDGMENT}

The authors would like to express their gratitude to Sri K.V.V. Satyanarayana Raju, Chairman, and Sri K. Sasi Kiran Varma, Managing Director, Chaitanya group of Institutions for encouraging to work at SRRFGIET Advanced labs.

\section{REFERENCES}

[1] Burt D. and Perrett D. Perception of age in adult Caucasian male faces: computer graphic manipulation of shape and colour information," Proceedings of the Royal Society of London, B259, pp.137-143, 1995.

[2] http://www.fgnet.rsunit.com

[3] Mark L. S. and Todd J. T. "The perception of growth in three dimensions," Journal of Perception and Psychophysics, Vol. 33(2), pp.193-196, 1983.

[4] Mark L. S., Pittenger J. B., Hines H. , Carello C. , Shaw R. E., and Todd J. T."Wrinkling and head shape as coordinated sources of age level information," Journal of Perception and Psychophysics, Vol. 27(2), pp.117-124, 1980.

[5] Pittenger J. B. and Shaw R. E. "Aging faces as visual-elastic events: Implications for a theory of no rigid shape perception," Journal of Experimental Psychology : Human Perception and Performance, Vol. 1(4), pp.374-382, 1975.

[6] Pittenger J. B., Shaw R. E. , and Mark L. S."Perceptual information for the age level of faces as a higher order invariant of growth," Journal of Experimental Psychology: Huffman Perception and Per-finance, Vol.5 (3), pp.478-493, 1979.

[7] Geng X., Zhou Z., and Smith-Miles K."Automatic age estimation based on facial aging patterns," IEEE Transactions on Pattern Analysis and Machine Intelligence, Vol.29 (12), pp. 2234-2240, Dec 2007.

[8] Kwon Y. H. and da Vitoria Lobo N "Age classification from facial images," Computer
Vision and Image Understanding, Vol. 74(1), pp.1$21,1999$.

[9] Lanitis A. , Taylor C. and Cootes T. "Toward automatic simulation of aging effects on face images," IEEE Transactions on Pattern Analysis and Machine Intelligence, Vol. 24(4), pp.442-455, April 2002.

[10] Lanitis A., Draganova C. and Christodoulou C. "Comparing different classifiers for automatic age estimation," IEEE Transactions on Systems, Man and Cybernetics - Part B, Vol.34 (1), pp.621-628, February 2004.

[11] Ramanathan N. and Chellappa R."Face verification across age progression," IEEE Transactions on image Processing, Vol. 15(11L), pp. 3349- 3361, November 2006.

[12] Ramanathan N. and Chellappa R. "Modeling age progression in young faces," In Proceedings of IEEE International conference on Computer Vision and Pattern Recognition, pp. 387-394, 2006.

[13] Scandrett C., Solomon C., and Gibson S."A person-specific, rigorous aging model of the human face," Pattern Recognition Letters, Vol 27(15), pp.1776-1787, November 2006.

[14] Suo J. , Min F. , Zhu S., Shan S. and Chen X."A multi-resolution dynamic model for face aging simulation," In IEEE Conference of Computer Vision and Pattern Recognition, pp.1-8, 2007.

[15] Wu Y. , Thalmaun N. and Thalimnann D. "A dynamic wrinkle model in facial animation and skin aging," Journal of Visualization and Computer Animation, Vol. 6, pp. 195-205, 1995.

[16] Mark L.S., Pittenger J.B., Hines, H., Carello, C., Shaw, R. E., and Todd, J. T. (1980). Wrinkling and head shape as coordinated sources of age level information. Journal Perception and Psychophysics, 27(2):117-124.

[17] Lanitis, A., Draganova, C., and Christodoulou, C. (2004). Comparing, Man, different classifiers for automatic age estimation. IEEE Transactions on Systems and Cybernetics, 34(1):621-628.

[18] Andreas Lanitis,(2008). Comparative evaluation of automatic age-progression methodologies. EURASIP J. Adv. Signal Process, 2008(2):1-10.

[19] Ahonen T., Hadid A. and Pietikainen M."Face Description with Local Binary Patterns: Application to Face Recognition," IEEE Trans. Pattern Anal. Mach. Intell., Vol. 28, no. 12, pp. $2037-2041,2006$.

[20] Haralick R. and Shapiro L."An Introduction to Nonlinear Image Processing," Vol.16, SPIE Optical Engineering Press, Washington, 1994.

[21] Haralick R. M."Statistical and structural approaches to texture," Proc. 4th Int. Joint Conf. Pattern Recognition,Vol.67, pp. 45-60, 1979.

[22] Alexander M. Bronstein, Michael M. et al."Expression-Invariant Representations of Faces," IEEE Transactions on Image Processing, Vol. 16, no. 1, January 2007. 


\section{Authors PROFILE}

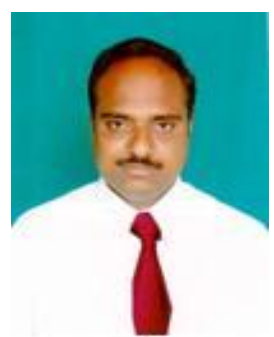

Dr. B. Eswara Reddy Graduated in B.Tech.(CSE) from Sri Krishna Devaraya University in 1995. He received Masters Degree in M.Tech. (Software Engineering), from JNT University, Hyderabad, in 1999. He received Ph.D in Computer Science \& Engineering from JNT University, Hyderabad, in 2008. He served as Assistant Professor from 1996 to 2006. He is working as Associate Professor in CSE Dept., since 2006 and currently acting as Head of CSE Dept. at JNTUACE, Anantapur. He has more than 30 Publications in various International Journals and Conferences. He is one of the author's of the text book titled Programming with Java published by Pearson/Sanguine Publishers. His research interests include Pattern Recognition \& Image Analysis, Data Warehousing \& Mining and Software Engineering. He is a life member of ISTE, IE, ISCA and member of CSI and IEEE.

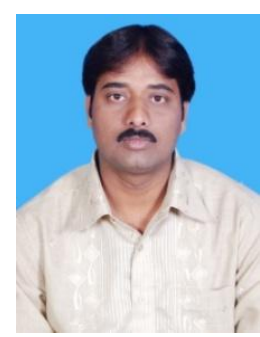

Mr. P.Chandra Sekhar Reddy completed his B.Tech in Computer Science \& Engineering from Sri Krishna Devaraya University in 1999.He Received the Masters Degree in M.Tech (Computer Science) from JNT University, Hyderabad, in 2004. He is pursuing his Ph.D in JNTUA University, Anantapur, India. He is currently working as Associate Professor in CSE Dept, GIET College of Engineering, Rajahmundry, India. He has having more than 11 years of Teaching Experience.His research areas are Image Processing and Pattern Recognition. He is a member of Professional bodies like IEEE,IAENG and SRRF.

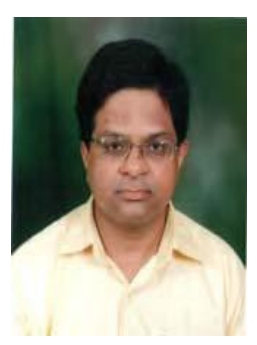

Vakulabharanam Vijaya Kumar received integrated M.S. Engg, degree from TashkentPolytechnic Institute (USSR) in 1989. He received his Ph.D. degree in Computer Science from Jawaharlal Nehru Technological University (JNTU) in 1998. He has served the JNTUniversity for 13 years as Assistant Professor and Associate Professor and taught courses for M.Tech students. He has been Dean for Computer Sciences and Head SRRF at Godavari Institute of Engineering and Technology since April, 2007.He has estabilished Srinivasa Ramanujan Research Forum(SRRF) at GIET with advanced lab facilities, which has become instrumental for many PG students and Research Scholars. Under SRRF-GIET so far ten scholars obtained Ph.D. His research interests include Image Processing, Pattern Recognition,
Network Security, Steganography, Digital Watermarking, and Image retrieval. He is a life member for CSI, ISTE, IE, IRS, ACS and CS. He has published more than 150 research publications in various National, Inter National conferences, proceedings and Journals. 